\title{
Analisa Faktor-Faktor Adopsi Inseminasi Buatan di Kecamatan Rengat Barat
}

\section{Analysis of Factors Affecting the Adoption of Artificial Insemination Innovation at Rengat Barat Sub-District}

\author{
Yendraliza*, M. Rodiallah, N. Darmagiri dan R. Misrianti \\ Fakultas Pertanian dan Peternakan Universitas Islam Negeri Sultan Syarif Kasim Riau \\ *E-mail: yendraliza@uin-suska.ac.id \\ (Diterima: 5 Februari 2018; Disetujui: 14 April 2018)
}

\begin{abstract}
ABSTRAK
Penelitian ini bertujuan untuk mengetahui evaluasi keberhasilan dan adopsi Inseminasi Buatan (IB) sapi potong di kecamatan Rengat Barat. Penelitian dilakukan pada bulan April 2017 di kecamatan Rengat Barat. Metode pengumpulan data adalah dengan wawancara menggunakan kuesioner dan observasi. Analisis data menggunakan analisis deskriptif dan adopsi IB dengan menggunakan analisis statistik inferensial regresi linier berganda (SPSS 16). Hasil penelitian menunjukkan keberhasilan IB sangat baik dengan $\mathrm{S} / \mathrm{C}$ berkisar 1,2-1,4 dengan persentase kebuntingan 75,5-86,1\%. Faktor adopsi IB meliputi tingkat pengetahuan tergolong tinggi dengan nilai bobot 216, motivasi tingkat sedang dengan bobot 179 dan tingkat biaya IB tergolong tinggi dengan bobot 197.
\end{abstract}

Kata kunci: adopsi IB, persentase kebuntingan, servis per konsepsi

\section{ABSTRACT}

This study was aimed at examining the factors affecting adoption of artificial insemination innovation among beef cattle farmers at Rengat Barat sub-district. The research was carried out on April 2017 using a survey method supported by questionnaire guidance and field observation. Collected data were analyzed by descriptive approach and the adoption of artificial insemination innovation using inferential statistical analysis of multiple linear regression (SPSS 16). The results showed that artificial insemination (AI) at Rengat Barat was success by $S / C$ indicators at the level of 1,2 to 1,4 and the pregnancy achievement at 75,5 to 86,1\%. Factors affecting AI adoption consisted of a high level of beef cattle farmers knowledge (216 point); a moderate degree of farmers motivation (179 point) and a the cost of AI innovation (197 point).

Keywords: adoption of artificial insemination (AI), innovation, pregnancy rate, service per conception

\section{PENDAHULUAN}

Sapi potong merupakan komoditas subsektor peternakan yang sangat potensial. Hal ini dapat dilihat dari tingginya konsumsi daging sapi dari 395.244 ditahun 2008 menjadi 593.706 di tahun 2013, dengan laju pertumbuhan $8.51 \%$ (Badan Pusat Statistik, 2014). Berdasarkan RPJMN bidang pangan dan pertanian 2015-2019, peningkatan konsumsi daging sapi ini kemungkinan disebabkan meningkatnya jumlah penduduk dan meningkatnya pendapatan penduduk Indonesia. Namun Indonesia belum mampu menyuplai semua kebutuhan daging sapi tersebut. Untuk mewujudkan program swasembada daging sapi maka diperlukan peningkatan populasi sapi potong dengan cara meningkatkan jumlah kelahiran pedet dan membatasi pemotongan induk sapi dalam jumlah besar. Program inseminasi buatan dapat dijadikan alternatif lain untuk menanggulangi permasalahan tersebut.

Dinas Peternakan dan Perikanan Kabupaten Indragiri Hulu (2015) melaksanakan inseminasi buatan di Rengat Barat sejak tahun 1981. Di Tahun yang sama dibangun pos Inseminasi Buatan (IB) 
Kabupaten Indragiri Hulu di desa Batugajah kecamatan Lirik. Adanya program IFAD, mempercepat perkembangan IB hingga seluruh kecamatan di Indragiri Hulu termasuk Rengat Barat. Berdasarkan Renstra Dinas Peternakan dan Kesehatan Hewan Provinsi Riau, Inhu merupakan salah satu Kabupaten pengembangan ternak sapi potong. Limapuluh dua persen populasi sapi potong di Inhu di suplai dari Kecamatan Rengat Barat.

Perkembangan IB belum memberikan dampak yang signifikan terhadap peningkatan populasi di Inhu. Hal ini kemungkinan disebabkan belum semua peternak di Inhu yang mengadopsi IB. Pengetahuan, minat dan harapan masyarakat sangat menentukan dalam melaksanakan program IB. Program Upaya Khusus Betina Wajib Bunting (UPSIWAB) merupakan upaya yang dilakukan pemerintah guna meningkatkan jumlah populasi sapi potong di Inhu. Informasi dari Dinas Kesehatan Hewan Provinsi Riau, target IB di Inhu adalah 5000 di tahun 2015 dan 1500 di tahun 2016.

Tujuan penelitian ini adalah melihat perkembangan IB di kecamatan Rengat Barat dan menganalisa factor-faktor adopsi IB di kecamatan Rengat Barat.

\section{METODE}

Penelitian dilaksanakan di Kecamatan Rengat Barat Kabupaten Indragiri Hulu Provinsi Riau. Evaluasi keberhasilan inseminasi buatan dilakukan dengan mengggunakandata akseptor inseminasi buatan tahun 2013, 2014 dan 2015 dengan total sampel pertahun 394 orang, 249 orang, 321 orang. Sampel faktor-faktor keberhasilan inseminasi buatan adalah menggunakan peternak yang telah melaksanakan IB sejak 5 tahun terakhir dan memiliki sapi yang telah beranak 2 kali. Total peternak yang dijadikan sampel adalah 77 peternak. Data yang digunakan terdiri dari data primer dan data sekunder. Teknik pengumpulan data terdiri dari wawancara, observasi dan dokumentasi.
Parameter yang diukur untuk evaluasi IB adalah service per conseption, conception rate dan non-return rate. Sedangkan parameter yang diukur untuk faktor-faktor yang mempengaruhi IB adalah pengetahuan, motivasi dan biaya. Data Evaluasi IB yang didapatkan dianalisis secara deskriptif dengan menampilkan rata-rata, standar deviasi dan persentase (Sugiono, 2009). Data faktor-faktor keberhasilan inseminasi buatan dianalisis menggunakan regresi linear berganda (Sugiono, 2009) menggunakan aplikasi SPSS 16. Model matematis dalam regresi linier berganda yaitu:

$$
\mathrm{Y}=\mathrm{a}+\mathrm{b}_{1} x_{1}+\mathrm{b}_{2} x_{2}++\mathrm{b}_{3} x_{3}
$$

Keterangan:

$$
\begin{array}{ll}
\mathrm{Y} & =\text { adopsi teknologi inseminasi buatan } \\
\mathrm{a} & =\text { koefisien intersep atau konstanta } \\
\mathrm{b}_{1} \mathrm{~b}_{2} \mathrm{~b}_{3} & =\text { koefisien regresi } \\
x_{1} & =\text { pengetahuan } \\
x_{2} & =\text { motivasi } \\
x_{3} & =\text { biaya inseminasi buatan }
\end{array}
$$

\section{HASIL DAN PEMBAHASAN}

\section{Profil Peternak}

Profil peternak di kecamatan Rengat Barat adalah $77,9 \%$ responden berjenis kelamin laki-Iaki dan 22,1 responden berjenis kelamin perempuan $75,3 \%$ berada pada tingkat umur produktif (15 -55 tahun) (Tabel 1). Sari dan Waluyo (2014) menyatakan bahwa minat dan keingin tahuan peternak dalam adopsi teknologi akan tinggi pada usia muda.

Tingkat pendidikan responden sebagian besar adalah tamat $\operatorname{SMA}(35,1 \%), 32,5 \%$ tamat SLTP, $20,8 \%$ tamat SD, $11,7 \%$ tidak tamat SD (Tabel 1).Tingkat pendidikan responden sudah tinggi sehingga memudahkan untuk menyerap teknologi yang diberikan. Abdullah et al. (2012) menyatakan bahwa semakin tinggi tingkat pendidikan peternak maka akan semakin tinggi kualitas sumberdaya manusia. Oleh karena itu, dengan semakin tingginya 
Tabel 1. Profil responden penelitian

\begin{tabular}{|c|c|c|c|}
\hline No & Uraian & Jumlah (orang) & Persentase $(\%)$ \\
\hline \multirow[t]{5}{*}{1} & Umur (tahun) & & \\
\hline & $<14$ & 0 & 0 \\
\hline & $15-55$ & 58 & 75,3 \\
\hline & $>55$ & 19 & 24,7 \\
\hline & Total & 77 & $100 \%$ \\
\hline \multirow[t]{4}{*}{2} & Jenis kelamin & & \\
\hline & Laki-laki & 60 & 77,9 \\
\hline & Perempuan & 17 & 22,1 \\
\hline & Total & 77 & $100 \%$ \\
\hline \multirow[t]{6}{*}{3} & Pendidikan & & \\
\hline & Tidak tamat SD & 9 & 11,7 \\
\hline & Tamat SD & 16 & 20,8 \\
\hline & Tamat SLTP & 25 & 32,4 \\
\hline & Tamat SLTA & 27 & 35,1 \\
\hline & Total & 77 & $100 \%$ \\
\hline \multirow[t]{4}{*}{4} & Jumlah tanggungan keluarga (orang) & & \\
\hline & $<5$ & 67 & 87 \\
\hline & $6-10$ & 10 & 13 \\
\hline & Total & 77 & $100 \%$ \\
\hline \multirow[t]{6}{*}{5} & Pengalaman beternak & & \\
\hline & $<5$ & 3 & 3,9 \\
\hline & $6-10$ & 42 & 54,5 \\
\hline & $11-20$ & 28 & 36,4 \\
\hline & $>21$ & 4 & 5,2 \\
\hline & Total & 77 & $100 \%$ \\
\hline
\end{tabular}

pendidikan peternak maka diharapkan kinerja usaha peternakan akan semakin berkembang. Menurut Cepriadi dan Edwina (2007) tingkat pendidikan yang relatif tinggi memungkinkan peternak mampu mengadopsi inovasi, penyuluhan serta bimbingan untuk meningkatkan usahanya.

Pengalaman beternak peternak Kecamatan Rengat Barat bervariasi, 3,9\% responden mempunyai pengalaman betemak selama 5 tahun, $54,5 \%$ responden mempunyai pengalaman betemak 6 - 10 tahun, 36,4\% responden yang mempunyai pengalaman ternak selama 11 - 20 tahun dan 5,2\% responden mempunyai pengalaman beternak lebih dari 21 tahun (Tabel 1). Pengalaman beternak sangat berpengaruh terhadap keberhasilan usaha. Sesuai dengan pendapat
Cepriadi dan Edwina (2007), bahwa semakin lama seseorang memiliki pengalaman beternak akan semakin mudah peternak mengatasi kesulitan-kesulitan yang dialaminya.

Jumlah tanggungan keluarga yang tinggi sebanyak $<5$ orang $(87 \%)$ dan $23 \%$ untuk jumlah tanggungan keluarga responden 6-10 orang. Semakin banyak jumlah tanggungan keluarga semakin banyak pula kebutuhan yang akan dipenuhi oleh keluarga, tapi disisi lain, semakin banyak tanggungan keluarga maka akan semakin banyak pula anggota keluarga yang akan membantu dalam usaha peternakan.

Nilai Evaluasi Inseminasi Buatan (IB)

Service Per Conception

Perhitungan jumlah S/C di Kecamatan

Analisa Faktor-Faktor Adopsi ... (Yendraliza et al.) 
Tabel 2. Nilai S/C pada tahun 2013, 2014 dan 2015

\begin{tabular}{ccccc}
\hline No & Tahun & Jumlah Service & S/C & StDev \\
\hline 1 & 2013 & 394 & 1,4 & $\pm 1,15$ \\
2 & 2014 & 249 & 1,3 & $\pm 1,11$ \\
3 & 2015 & 321 & 1,2 & $\pm 1,08$ \\
\hline
\end{tabular}

Tabel 3. Hasil CR pada tahun 2013, 2014 dan 2015

\begin{tabular}{ccccc}
\hline No & Tahun & Jumlah Akseptor & CR & StDev \\
\hline 1 & 2013 & 374 ekor & $75,5 \%$ & $\pm 14,36$ \\
2 & 2014 & 315 ekor & $83,8 \%$ & $\pm 10,54$ \\
3 & 2015 & 450 ekor & $86,1 \%$ & $\pm 5,91$ \\
\hline
\end{tabular}

Rengat Barat ditinjau dari tahun 2013, 2014 dan 2015 adalah 1,4, 1,3, 1,2. Artinya setiap satu kali perkawinan sapi potong di Rengat Barat menghasilkan satu kebuntingan. Nilai ini tergolong sangat baik (Hafez, 2016).

Baiknya nilai $\mathrm{S} / \mathrm{C}$ di daerah ini tidak terlepas dari kerja inseminator yang selalu aktif dalam mengontrol ternak yang yang berahi setelah adanya laporan peternak (Tabel 2). Disamping itu juga disebabkan karena peternak sudah mengetahui dengan jelas tanda-tanda berahi dan waktu yang tepat untuk mengawinkan sapinya (Hafez, 2016) selanjutnya Gordon (2016) menyatakan bahwa bahwa S/C ternak yang di IB dipengaruhi oleh lingkungan, kemampuan ternak dalam beradaptasi dengan lingkungannya.

Nilai S/C yang didapatkan pada penelitian ini didukung sistem pemeliharaan ternak yang menggunakan sistem semi intensif menyebabkan berahi ternak betina dapat dikontrol dengan baik.

\section{Conception Rate (CR)}

Persentase kebuntingan pada inseminasi satu kali (40-60 hari) dengan persentanse terendah terjadi pada tahun 2013 yaitu sebesar 75,5\%. Pada tahun 2014 nilai CR adalah sebesar 83,8\% dan tahun 2015 adalah $86,1 \%$ (Tabel 3).

Nilai CR sapi potong di Kecamatan Rengat Barat sudah baik. Menurut Toelihere (1993) CR terbaik mencapai 60-70\%, sedangkan untuk ukuran Indonesia dengan mempertimbangkan kondisi alam, manajeman dan distribusi ternak yang menyebar sudah dianggap baik jika nilai CR mencapai 45$50 \%$.

Nilai CR sapi potong di Rengat Barat ini lebih rendah dari nilai CR sapi potong di Tadulako 93,3 \% (Kusrianty et al., 2016) namun lebih tinggi dari CR sapi potong di Jawa Barat pada tahun 2003 - 2007, 61,37\% - 46,67\% (Rasad et al., 2008). Perbedaan ini kemungkinan disebabkan oleh jenis sapi potong, peternak dan daerah penelitian berbeda (Tolihere, 1993).

Tingginya kesadaran peternak akan reproduksi terlihat dari pencatatan (recording) yang rapi. Selain itu Kecamatan Rengat Barat memiliki 3 orang petugas IB. sehingga dapat menjangkau seluruh lokasi Kecamatan Rengat Barat. Partodihardjo (1992) mengemukakan bahwa ada beberapa hal yang dapat mempengaruhi angka kebuntingan antara lain penyakit, kesuburan betina, keterampilan inseminator dan waktu inseminasi.

\section{Faktor- Faktor Adopsi Inseminasi Buatan Peternak Sapi Potong \\ Pengetahuan}

Syatra et al. (2016) menyatakan bahwa secara umum pengetahuan peternak dapat diukur dari nilai manfaat yang dirasakan oleh peternak terhadap adopsi teknologi inseminasi buatan meliputi manfaat dari teknologi inseminasi buatan. Ketepatan waktu inseminasi buatan, pengenalan tanda-tanda 
Tabel 4. Pengetahuan peternak terhadap adopsi teknologi IB di Kecamatan Rengat Barat

\begin{tabular}{clcccc}
\hline No & Keterangan & Skor & Frekuensi (Orang) & Persentase (\%) & Bobot \\
\hline 1 & Tinggi & 3 & 62 & 80,5 & 186 \\
2 & Sedang & 2 & 15 & 19,5 & 30 \\
3 & Rendah & 1 & 0 & 0 & 0 \\
\hline & Jumlah & & 77 & $100 \%$ & 216 \\
\hline
\end{tabular}

Sumber: Data primer yang diolah (2017)

Tabel 5. Minat peternak terhadap adopsi teknologi IB di Kecamatan Rengat Barat

\begin{tabular}{clcccc}
\hline No & Keterangan & Skor & Frekuensi (Orang) & Persentase (\%) & Bobot \\
\hline 1 & Tinggi & 3 & 27 & 35,1 & 81 \\
2 & Sedang & 2 & 35 & 45,4 & 70 \\
3 & Rendah & 1 & 15 & 19,5 & 15 \\
\hline & Jumlah & & 77 & $100 \%$ & 116 \\
\hline
\end{tabular}

berahi pada sapi betina dan keahlian dari inseminator dalam melaksanakan inseminasi buatan merupakan factor penentu keberhasilan inseminasi buatan (Hafez, 2016).

Nilai bobot pengetahuan sebesar $87 \%$ dan berada pada interval antara 186,5-241 dengan kategori tinggi (Tabel 4). Hal ini memperlihatkan bahwa pengetahuan peternak tentang kawin tepat waktu dan ciri-ciri berahi pada ternak sudah baik. Sesuai Hastuti (2008), bahwa tingkat keberhasilan inseminasi buatan sangat dipengaruhi oleh empat faktor yang saling berhubungan yaitu pemilihan sapi akseptor, pengujian kualitas semen, akurasi deteksi birahi oleh para peternak dan keterampilan inseminator. Peternak yang memiliki pengetahuan yang tinggi akan memudahkan dalam mengadopsi teknologi inseminasi buatan. Yunasaf dan Tasripin (2011) menyatakan bahwa semakin tinggi tingkat pengetahuan, maka semakin mudah melakukan adopsi terhadap inovasi baru.

\section{Motivasi}

Motivasi peternak dapat diukur dari minat dan harapan.

\section{Minat}

Syatra et al. (2016) menyatakan bahwa ukuran minat peternak dalam program inseminasi buatan dapat dilihat dari rasa ingin tahu, kesadaran yang tinggi dan keterlibatan dalam penyelenggaraan inseminasi buatan.

Minat peternak tehadap teknologi inseminasi buatan di Kecamatan Rengat Barat dalam interval sedang (Tabel 5). hal ini menunjukkan bahwa informasi tentang IB belum sampai ke masyarakat secara terstrukur dan massif. Informasi ini baru terjadi dari mulut ke mulut peternak. Menurut Yunasaf dan Tasripin (2011), bahwa materi penyuluhan yang baik adalah materi penyuluhan yang didasarkan pada kebutuhan peternak dan memecahkan permasalahan peternak.

\section{Harapan}

Harapan diukur dari peningkatan kesejahteraan peternak, peningkatan ketrampilan peternak dan peningkatan produktivitas ternak (Syatra et al., 2016).

Persentase nilai harapan peternak di Kecamatan Rengat Barat terhadap adopsi teknologi inseminasi buatan terlihat bahwa 40 orang peternak menyatakan tinggi $(51,9 \%)$, 35 orang peternak menyatakan sedang $(45,4 \%)$ dan 2 orang peternak menyatakan rendah (2.6\%) (Tabel 6). Sehingga total nilai bobot untuk harapan peternak terhadap adopsi teknologi inseminasi buatan sebesar 192. Hal ini menjelaskan bahwa harapan peternak terhadap teknologi inseminasi buatan dapat meningkatkan produktivitas ternak, dapat mensejahterakan peternak sapi potong dan 
Tabel 6. Harapan peternak terhadap adopsi teknologi IB di Kecamatan Rengat Barat.

\begin{tabular}{clcccc}
\hline No & Keterangan & Skor & Frekuensi (Orang) & Persentase (\%) & Bobot \\
\hline 1 & Tinggi & 3 & 40 & 51,9 & 120 \\
2 & Sedang & 2 & 35 & 45,4 & 70 \\
3 & Rendah & 1 & 2 & 2,6 & 2 \\
\hline & Jumlah & & 77 & $100 \%$ & 192 \\
\hline
\end{tabular}

Sumber: Data primer yang telah diolah (2017)

Tabel 7. Hasil penilaian motivasi peternak terhadap adopsi teknologi IB diKecamatan Rengat Barat.

\begin{tabular}{clcc}
\hline No & Indikator penilaian & Bobot & Kategori \\
\hline 1 & Minat & 166 & Sedang \\
2 & Harapan & 192 & Tinggi \\
\hline & Rata-rata & 179 & Sedang \\
\hline
\end{tabular}

Sumber: Data primer yang telah diolah (2017)

dapat mengembangkan jumlah ternak sapi potong itu sendiri.

\section{Penilaian Movitasi Peternak}

Motivasi peternak di Kecamatan Rengat Barat cukup tinggi terhadap tingkat adopsi teknologi inseminasi buatan. Hal ini ditunjukkan oleh minat peternak untuk mengetahui program inseminasi buatan dan keterlibatan peternak dalam program inseminasi buatan dengan mengikuti pelaksanaan inseminasi buatan dan kegiatan penyuluhan (Tabel 7). Adapun faktor lain yang menyebabkan tingginya minat peternak adalah sebagian peternak berada pada usia produktif yaitu dengan persentase sebesar $75,3 \%$. Penduduk usia produktif berada pada masa cepat menangkap informasi yang baru dan haus akan ilmu pengetahuan.

\section{Biaya Inseminasi Buatan (IB)}

Menurut Syatra et al. (2016), biaya inseminasi buatan adalah nilai yang harus dikeluarkan peternak untuk menggunakan jasa inseminator dalam pengembangan ternak melalui teknologi inseminasi buatan.

Sebagian besar peternak di Kecamatan Rengat Barat menilai biaya IB terhadap adopsi teknologi inseminasi buatan tinggi (Tabel 8). Semakin tinggi minat peternak dalam mengeluarkan biaya dalam pelaksanaan inseminasi buatan maka semakin rendah biaya yang dikeluarkan peternak dalam pelaksanaan program IB tersebut. Karena tingginya minat peternak terhadap biaya menunjukkan bahwa biaya pelaksanaan IB terjangkau oleh peternak di Kecamatan Rengat Barat. Pada umumnya peternak menginginkan biaya inseminasi yang rendah namun mempunyai kualitas pelayanan yang baik. Adapun pelayanan yang diharapkan oleh peternak yaitu inseminator mendatangi langsung ternak yang ingin di inseminasi dan ternak betina yang dikawinkan menggunakan jasa inseminator cukup sekali inseminasi untuk menghasilkan kebuntingan.

Hasil analisis regresi linear berganda faktor-faktor yang mempengaruhi keberhasilan IB di Kecamatan Rengat Barat adalah:

$$
\mathrm{Y}=2,120+0,164 \mathrm{x}_{1}+0,214 \mathrm{x}_{2}+0,290 \mathrm{x}_{3}
$$

Variabel pengetahuan dan motivasi memiliki masing-masing signifikasi $\alpha=0,015$ dan 0.007 yang menunjukan nilainya lebih kecil dari taraf signifikasi pada $\alpha=0,05$ (Tabel 9). Artinya pengetahuan, motivasi memiliki pengaruh yang signifikan terhadap tingkat adopsi Inseminasi buatan (IB). Namun, pada variabel biaya IB memiliki nilai signifikasi $\alpha$ $=0,241$ yang menunjukan nilai tersebut lebih besar dari taraf signifikasi pada $\alpha=0,05$. 
Tabel 8. Biaya IB peternak terhadap adopsi teknologi IB di Kecamatan Rengat Barat

\begin{tabular}{clcccc}
\hline No & Keterangan & Skor & Frekuensi (Orang) & Persentase (\%) & Bobot \\
\hline 1 & Tinggi & 3 & 46 & 59,7 & 138 \\
2 & Sedang & 2 & 28 & 36,4 & 56 \\
3 & Rendah & 1 & 3 & 3,9 & 0 \\
\hline & Jumlah & & 77 & $100 \%$ & 197 \\
\hline
\end{tabular}

Tabel 9. Analisis Regresi Linear Berganda

\begin{tabular}{lcccccc}
\hline Variable Penelitian & $\begin{array}{c}\text { Koefisien } \\
\text { Regresi }\end{array}$ & $\begin{array}{c}\text { Koefisien } \\
\text { Korelasi }\end{array}$ & & t Hitung & Korelasi & Ket \\
\hline Pengetahuan (X1) & 0,141 & 0,164 & 0,026 & 1,424 & 0,015 & Sig \\
Motivasi (X2) & 0,129 & 0,214 & 0,045 & 1,869 & 0,007 & Sig \\
Biaya IB (X3) & 0,160 & 0,290 & 0,084 & 0,246 & 0,241 & Ns \\
\hline F Hitung $=$ & 2,873 & & R & $=0,320$ & $=0,106$ & \\
F Tabel $\quad=$ & 2,730 & & Const & $=2,120$ & & \\
t Tabel & 1,993 & & Sig $\alpha$ & $=0,05$ & & \\
\hline
\end{tabular}

Artinya biaya IB tidak memiliki pengaruh terhadap adopsi IB.

$$
\text { Pengujian secara simultan }
$$
menggunakan uji $\mathrm{F}$ diperoleh bahwa nilai $\mathrm{F}$ hitung sebesar 2,873 yang nilainya lebih besar dari F Tabel 2,730. Hal ini menunjukan bahwa variabel pengetahuan, motivasi dan biaya IB memiliki pengaruh terhadap tingkat adopsi IB. Dari uji korelasi, nilai koefisien determinan (R2) sebesar 0,106 atau 10,6\% termasuk kedalam kategori korelasi lemah artinya terdapat variabel lain sebesar 89,4 $\%$ yang mempengaruhi tingkat adopsi IB peternak sapi potong di Kecamatan Rengat Barat diluar variabel pengetahuan, motivasi dan biaya IB.

\section{KESIMPULAN}

Keberhasilan IB sangat baik dengan $\mathrm{S} / \mathrm{C}$ berkisar 1,2-1,4 dengan persentase kebuntingan 75,5-86,1\%. Faktor Adopsi IB meliputi tingkat pengetahuan tergolong tinggi dengan nilai bobot 216, motivasi tingkat sedang dengan bobot 179 dan tingkat biaya IB tergolong tinggi dengan bobot 197 .

\section{DAFTAR PUSTAKA}

Abdullah, A., Aminawar, M., Hoddi, H.A., Ali, H.M. dan Syamsu, J.A. 2012. Identifikasi kapasitas peternak dalam adopsi teknologi untuk pengembangan sapi potong yang terintegrasi dengan padi. Prosiding Seminar Nasional Peternakan Berkelanjutan IV "Inovasi Agribisnis Peternakan Untuk Ketahanan Pangan" Fakultas Peternakan Universitas Padjadjaran tanggal 12 September 2012. 1- 10.

Cepriadi dan Edwina, S. 2007. Analisis Pendapatan Peternak Ayam Broiler Pola Kemitraan di Kota Pekanbaru. $J$. Pet. 4(1): 20-29.

Gordon, I. 2016. Reproductive Technologies In Farm Animals, 2nd Edition. Https://Books. Google.Co.Id/ Books?Isbn=178064602X

Hafez. E. S. 2016. Reproduction In Farm Animals. Ed.Lea and Febiger, Philadelpia. DOI: 10.1002/9781119265306.ch10

Hastuti, D. 2008. Tingkat Keberhasilan Inseminasi Buatan Sapi Potong di Tinjau dari Angka Konsepsi dan Service per Conception. J. Mediagro. 4 
(1): $12-20$

Tolihere, R. M. 1993. Ilmu Kebidanan pada Ternak Sapi dan Kerbau. UI Press, Jakarta.

Sari, A. I. dan Waluyo 2014. Penguatan sosial ekonomi masyarakat lereng merapi melalui adopsi inovasi pupuk organik untuk mendukung sistem pertanianpeternakan terpadu. Buana Sains. 14(2): 165-174.

Sugiono. 2009. Statistik untuk Penelitian. CV. Alfabeta, Bandung.

Syatra, U., Kasim, S. N. K. dan Asnawi, A. 2016. Pengaruh Pengetahuan, Motivasi, dan Biaya Inseminasi Buatan Terhadap Adopsi Teknologi IB Peternak Sapi Potong di Desa Waji Kecamatan Tellu Siattinge Kabupaten Bone. JIIP. 3 (2):71-76.
Kusrianty, Mirajuddin dan Awalludin. 2016. Efektifitas Inseminasi Buatan Pada Sapi Potong Menggunakan Semen Cair Nelly. Mitra Sains, 4(1):50-57.

Partodihardjo, S. 1992. Ilmu Reproduksi Hewan. Cetakan ke-3 Penerbit Mutiara Sumber Widia, Jakarta.

Rasad, S.D., Kuswaryan, S., Sartika, D., Salim, R. 2008. Kajian Pelaksanaan Inseminasi Buatan pada sapi potong di Jawa Barat. Prosiding Seminar Nasional Sapi Potong Palu, 24 November 2008: 104-114.

Yunasaf, U. dan Tasripin, D.S. 2011. Peranan penyuluh dalam proses pembelajaran peternak sapi perah di KSU Tandangsari Sumedang. Jurnal Ilmu Ternak. 11(2): 98-103. 